\title{
INTERVENÇÃO FONOAUDIOLÓGICA COM GÊNEROS TEXTUAIS EM UM GRUPO DE ESCOLARES
}

\author{
Speech Therapy intervention with textual genders \\ in a group of school age children
}

\author{
Ane Caroline Brisch Schneider (1), Ana Paula Ramos de Souza ${ }^{(2)}$, Vanessa Panda Deuschle ${ }^{(3)}$
}

\begin{abstract}
RESUMO
Tema: terapia com gêneros textuais em um grupo de escolares. Objetivos: analisar os resultados terapêuticos a partir da introdução de gêneros textuais como funcionamento terapêutico em um grupo de escolares com queixa de distúrbios de aquisição da linguagem escrita. Procedimentos: participaram deste estudo cinco sujeitos, matriculados na $5^{\underline{a}}$ ou $6^{\underline{a}}$ série do ensino fundamental, em escolas distintas da rede pública de ensino da cidade de Santa Maria/RS, com idade entre 10 e 13 anos e histórico de fracasso escolar e repetência. A análise da produção textual com temática livre foi realizada por meio do protocolo de Lubian (2007). A intervenção terapêutica se deu entre setembro de 2007 e junho de 2008. Ao término do trabalho terapêutico a produção textual foi novamente analisada segundo o mesmo protocolo. Resultados: o trabalho com gêneros textuais facilitou a motivação para ler e escrever e teve, como consequência, a melhoria da progressão e coesão textuais, além da adequação dos aspectos formais da escrita como ortografia e pontuação. O trabalho em grupo foi essencial para que os integrantes pudessem ressignificar os sentidos atribuídos à queixa a partir de constante diálogo com troca de experiências de situações escolares e familiares. Conclusão: a terapia com gêneros textuais foi motivador para outras práticas de leitura e escrita no grupo estudado. Além disso, o estudo de casos demonstra que não se tratam de distúrbios, mas práticas de letramento insuficientes.
\end{abstract}

DESCRITORES: Transtornos de Aprendizagem; Linguagem; Fonoterapia; Leitura; Escrita Manual

\section{INTRODUÇÂO}

A aquisição da linguagem escrita tem início antes da entrada na escola, tornando-se formal por volta do sétimo ano de vida das crianças. Contudo, muitas delas não conseguem se apropriar de

(1) Aluna do Curso de Graduação em Fonoaudiologia da Universidade Federal de Santa Maria, UFSM, Santa Maria, RS.

(2) Fonoaudióloga; Professora do Curso de Graduação em Fonoaudiologia e do Programa de Pós-Graduação em Distúrbios da Comunicação Humana da Universidade Federal de Santa Maria, UFSM, Santa Maria, RS; Doutora em Linguística Aplicada pela Pontifícia Universidade Católica do Rio Grande do Sul.

(3) Fonoaudióloga da Secretaria Municipal de Saúde de São Francisco de Assis, RS; Especialista em Fonoaudiologia pela Universidade Federal de Santa Maria; Mestranda em Distúrbios da Comunicação Humana na Universidade Federal de Santa Maria.

Conflito de interesses: inexistente forma efetiva da escrita, e passam a ver esta como algo difícil de ser aprendido. A escola, por sua vez, acaba por rotular estas crianças como "maus alunos", "alunos problema", "desatentos", "indisciplinados" e até mesmo "disléxicos". Esses rótulos, na maioria dos casos, prejudicam ainda mais o desenvolvimento das crianças, pois estas passam a acreditar que possuem uma patologia que as impedirá de aprender com sucesso ${ }^{1}$. No entanto, sabe-se que a grande maioria dos casos de distúrbios de leitura e escrita tem como causa principal práticas de letramento limitantes, insuficientes, ou até mesmo ausentes ${ }^{2}$. Em geral, as práticas textuais são descontextualizadas, com enfoque principal, por parte do professor, nos aspectos ortográficos na correção textual $^{3}$.

Na prática fonoaudiológica tem sido usual, nas abordagens de escrita como código, observar a mesma dinâmica de ensino escolar. $O$ trabalho fonoaudiológico que enfoca a escrita, usualmente, 
toma como unidade principal de trabalho a palavra, sem investir em abordagens que considerem as dificuldades na construção textual. Em extensa revisão de literatura acerca da produção científica fonoaudiológica nacional sobre a linguagem escrita, autores concluíram que a produção que relacione a linguagem escrita e a escola foi a menos abordada nas publicações ${ }^{4}$. Em contrapartida, estudos envolvendo habilidades neurobiológicas como a memória ${ }^{5}$ e consciência fonológica ${ }^{6,7}$ foram temas frequentes, nos quais a unidade de análise em geral é a palavra e não o texto. Além desses, há propostas terapêuticas via metodologias que privilegiam a fonologia e/ou articulação ${ }^{8,9}$, no entanto, estes comumente não levam em consideração o texto como unidade de análise ${ }^{10-14}$.

Alguns autores observaram que a vivência realizada pelas crianças em relação às práticas de escrita diferenciadas daquelas presentes na escola tradicional, optando ainda pela visitação a diversos gêneros discursivos, mostrou-se como um caminho frutífero para o trabalho terapêutico fonoaudiológico ${ }^{15}$.

Tais trabalhos se filiam a perspectivas teóricas do campo sócio-interacionista ou interacionista, a partir das quais abordagens terapêuticas têm-se mostrado efetivas. Exemplos dessa efetividade são as terapêuticas com sujeitos surdos ${ }^{16-18}$, com síndrome de Down ${ }^{19}$ e afásicos ${ }^{20}$. Tais estudos apresentam princípios básicos como a busca da funcionalidade da escrita nas atividades diárias do sujeito, o erro como evidência da formulação de hipóteses durante o processo de aquisição da escrita, a mútua dependência entre fala e escrita, em que uma modalidade interroga e alimenta a outra. Todos os trabalhos ressaltam a importância do fonoaudiólogo buscar uma prática diferenciada daquela usualmente feita na escola. Alguns sugerem que esse novo fazer clínico pode ser acessado pela escola por meio de um trabalho de assessoria do fonoaudiólogo a esta ${ }^{21}$. Também aspectos ligados à terapia em grupo são abordados em trabaIhos dessa perspectiva teórica ${ }^{22}$.

Em algumas dessas pesquisas, citado de modo explícito ou não, o conceito de gênero está presente. A base deste conceito é a percepção de que todos os campos da linguagem estão ligados ao uso da mesma, e que este se dá de modo multiforme, na forma de enunciados orais e escritos. Estes possuem um estilo, um conteúdo temático e uma construção composicional que se relaciona com o campo de comunicação no qual é utilizado. Esses campos elaboram tipos relativamente estáveis que são os gêneros discursivos ${ }^{23}$.

Para este trabalho privilegiou-se uma perspectiva sócio-interacionista, a qual aponta que é por meio da relação com o outro que o aprendiz subjetiva-se e relaciona-se com a escrita como um objeto de conhecimento ${ }^{23}$. Inserido nesse contexto teórico, o presente estudo de caso tem como objetivo, analisar a eficácia do trabalho terapêutico com gêneros textuais em um grupo de pré-adolescentes matriculados no terceiro ciclo do ensino fundamental com queixa de dificuldade de aquisição da linguagem escrita, observando a evolução do domínio da escrita pelos sujeitos, em especial a evolução na produção textual.

\section{APRESENTAÇÃO DO CASO}

Participaram deste estudo cinco sujeitos, sendo destes, três sujeitos do sexo masculino e dois do sexo feminino, matriculadas na $5^{\underline{a}}$ ou $6^{\underline{a}}$ série do ensino fundamental, em escolas distintas da rede pública de ensino da cidade de Santa Maria/RS, que buscaram a clínica-escola de uma Universidade. A idade cronológica foi de 10 a 13 anos, sem alteração no desenvolvimento da linguagem, com histórico de fracasso escolar e repetência.

Foram excluídos da pesquisa os sujeitos que apresentaram distúrbios de escrita/aprendizagem relacionados a grandes transtornos do desenvolvimento tais como deficiência mental, paralisia cerebral, autismo, psicose, ou mesmo a déficits sensoriais como a surdez e cegueira. Também foram excluídos aqueles que não completaram as avaliações ou foram desligados do serviço por excesso de faltas.

A descrição dos sujeitos foi realizada a partir das entrevistas iniciais com os responsáveis pelos mesmos.

Sujeito 1: A.P.R., sexo feminino, 10 anos de idade. Segundo o pai a gravidez foi planejada, sem intercorrências, porém acompanhada do hábito de tabagismo da mãe. O parto foi a termo e sem complicações. Quanto ao desenvolvimento neuropsicomotor, não houve particularidades. A. reside com a mãe e três irmãos, filhos do segundo casamento da mãe. Quanto ao desempenho escolar, sempre foi satisfatório, mas depois do falecimento de um tio próximo, há dois anos, começou a apresentar dificuldades na escola.

Em entrevista quanto aos hábitos de leitura em casa, a mãe relatou que, sempre que possível, realiza atividades de leitura com seus filhos, como histórias infantis, revistas e jornais, e acredita que esta iniciativa é essencial para o bom desenvolvimento escolar de A. A mãe relatou também que a leitura não é uma atividade pessoal de entretenimento, e sim a realiza em função dos filhos. 
A menina já realizou acompanhamento psicológico e não teve nenhum atendimento fonoaudiológico anterior a este.

Sujeito 2: A.N.S., sexo masculino, 10 anos de idade. A mãe relatou que a gravidez não foi planejada e que fez uso de medicação abortiva. O parto se deu sem intercorrências, e a amamentação natural foi ofertada apenas até do $15^{\circ}$ dia de vida do bebê, segundo ela por falta de paciência com o filho. O quarto é dividido com a mãe, o padrasto e os três irmãos, sendo que a cama é dividida com os irmãos. Faz uso da medicação Imipramina, receitada pelo seu médico.

Em entrevista sobre as práticas de letramento familiar, a mãe relatou que não há o hábito de leitura em casa e que "desistiu do filho e de comprar livros para ele, por que ele estraga tudo". Ela em nenhum momento referiu à leitura como uma atividade adequada para o bom desenvolvimento do filho, e sim como algo extremamente complicado e difícil de ser executado.

Anteriormente a este atendimento frequentou outro serviço fonoaudiológico e psicopedagógico.

Sujeito 3: D.A, sexo feminino, 11 anos de idade. A mãe referiu que a gestação não foi planejada, o parto foi a termo e com complicações, sendo que a menina necessitou de oxigênio por dois dias. $\mathrm{O}$ desenvolvimento neuropsicomotor se deu com algumas dificuldades motoras da criança. Fez uso de mamadeira até os nove anos de idade e chupeta até os sete anos. Apresenta trocas de sonoridade na fala e na escrita. Repetiu a $4^{a}$ série do ensino fundamental, e segundo a mãe seu desempenho escolar não é bom.

Quanto aos hábitos de letramento, a mãe relatou que não gosta de ler e que nunca se preocupou em aguçar este hábito nos filhos, ela acredita que esta é uma atividade que a escola deve desenvolver.

Sujeito 4: M.S.A, sexo masculino, 13 anos de idade. Em entrevista com os pais, relataram que a gravidez foi planejada e tranquila, o parto se deu de forma normal, sem intercorrências. Segundo a mãe, o bebê teve muita dificuldade em sugar o seio materno logo nos primeiros dias. Em relação ao desenvolvimento neuropsicomotor, referiram que o bebê "atrasou para tudo". Durante o sono apresenta bruxismo, ronca e baba. Apresenta, também, dificuldades em realizar algumas atividades diárias, como amarrar os sapatos. Tem diagnóstico de Déficit de Atenção e Hiperatividade e faz uso de medicação Ritalina, mas esta foi suspensa pela mãe. Foi diagnosticado pela psicopedagoga como disléxico. Tem histórico escolar de repetência na $1^{\text {a }}$ e $5^{\text {a }}$ séries.

A mãe relatou que não tem o hábito de leitura diária de livros, jornais ou revistas, mas que gosta de fazê-lo e sempre que possível busca se atualizar.
Frequentemente oferta livros ao filho e o estimula a fazer leituras diárias. Acredita que esta atividade é muito importante para o desenvolvimento do filho.

Sujeito 5: T.O., sexo masculino, 12 anos de idade. A mãe relatou em entrevista que a gestação foi planejada, esta se deu sem intercorrências, porém o menino nasceu com o cordão umbilical enrolado no pescoço. O desenvolvimento neuropsico-motor foi normal. O menino apresenta sono agitado, acompanhado por apneias. Repetiu a $3^{\text {a }}$ série duas vezes. Seguindo a indicação escolar a mãe já buscou atendimento psicológico e neurológico.

Quanto às atividades de leitura em casa, a mãe relatou que não tem o hábito de ler, mas procura fazer com que o filho leia os materiais exigidos pela escola. Não cita, em nenhum momento, que as práticas de leitura são importantes para o bom desempenho escolar do filho.

As avaliações incluíram aspectos da textualidade (compreensão e produção de textos), bem como aspectos neuropsicológicos (consciência fonológica, memória auditiva, identificação de rotas de leitura e escrita) ${ }^{24}$, estas últimas realizadas por fazerem parte da rotina de triagem inicial do serviço. Cabe ressaltar que o desempenho nas mesmas foi considerado dentro dos padrões esperados para o nível de escolaridade dos sujeitos. Para a análise deste artigo, foram consideradas apenas aquelas de foco textual, de modo especial a produção, já que a compreensão estava adequada ao início do processo terapêutico.

O trabalho terapêutico foi realizado no período de setembro de 2007 a junho de 2008, com um período de férias entre dezembro de 2007 e abril de 2008. Os atendimentos se deram em duas etapas, no ano de 2007 as crianças foram atendidas formando um único grupo, por uma hora e trinta minutos semanalmente. Em 2008, por motivos escolares, o grupo foi dividido em dois, com atendimentos de uma hora semanal. A intervenção ocorreu em 30 sessões terapêuticas. Houve uma avaliação intermediária, entre a inicial e a final apresentadas neste artigo, para novo planejamento no mês de abril, quando o grupo foi desmembrado.

Os atendimentos foram realizados por uma aluna do último ano de graduação do Curso de Fonoaudiologia da instituição de ensino, que recebeu aulas teóricas e supervisão com docente experiente na prática clínica com sujeitos com queixa de distúrbio na aquisição da linguagem escrita.

Antes da constituição do grupo, foi realizada avaliação individual da produção textual, que se deu de dois modos: pela evocação a partir de tira de humor e pela produção livre de uma lauda sobre tema de interesse de cada sujeito. 
Tabela 1 - Análise dos Níveis de Textualidade proposta por Lubian (2007)

\begin{tabular}{|c|c|}
\hline \multicolumn{2}{|r|}{ NÍVEIS DE TEXTUALIDADE NAS PRODUÇÕES TEXTUAIS } \\
\hline I - Intencionalidade & $\begin{array}{l}1.1-\text { O texto é neutro não demonstrando nenhuma intencionalidade. } \\
1.2-\text { O texto demonstra intencionalidade inicial. } \\
1.3-\text { O texto é claro em sua intencionalidade. }\end{array}$ \\
\hline II - Situacionalidade & $\begin{array}{l}2.1 \text { - O texto não é relevante ao contexto de sua produção. } \\
2.2 \text { - O texto apresenta uma relevância parcial. } \\
2.3 \text { - O texto é relevante ao contexto de produção. }\end{array}$ \\
\hline III - Aceitabilidade & $\begin{array}{l}\text { 3.1 - O texto não reflete a preocupação do autor em ser claro para os leitores. } \\
\text { 3.2 - O texto traz uma preocupação parcial do autor em ser claro para os } \\
\text { leitores. } \\
\text { 3.3 - O texto reflete a preocupação do autor em ser claro para os leitores. }\end{array}$ \\
\hline IV - Não-contradição & $\begin{array}{l}\text { 4.1 - O texto apresenta muitas contradições. } \\
4.2 \text { - O texto apresenta contradições esporádicas. } \\
4.3 \text { - O texto não apresenta contradições. }\end{array}$ \\
\hline V - Repetição & $\begin{array}{l}5.1 \text { - O texto não apresenta repetições bem coordenadas (o autor não faz } \\
\text { bom uso de elementos coesivos.). } \\
5.2 \text { - O texto apresenta parcialmente o uso de elementos coesivos. } \\
5.3 \text { - O texto apresenta mecanismos coesivos sempre que necessário. }\end{array}$ \\
\hline VI - Progressão & $\begin{array}{l}6.1 \text { - O texto não apresenta progressão, sendo repetitivo ao extremo. } \\
6.2 \text { - O texto apresenta progressão parcial, apresentando algumas repetições } \\
\text { desnecessárias. } \\
6.3 \text { - O texto apresenta progressão total, com significados novos e sem } \\
\text { repetições desnecessárias. }\end{array}$ \\
\hline
\end{tabular}

Fonte: Lubian ME. Processo de produção textual em uma proposta transdisciplinar na $4^{a}$ série do ensino fundamental. [dissertação]. Passo Fundo (RS): Universidade de Passo Fundo (UPF); 2007.

As análises qualitativas das produções escritas foram feitas a partir dos níveis textuais propostos pela linguística textual ${ }^{25}$. Além da atribuição de níveis, observações qualitativas de aspectos textuais como elementos coesivos, pontuação, noções temporais, vocabulário e traçado da letra, foram realizadas. As características textuais e a classificação proposta são apresentadas na Tabela 1.

Os procedimentos terapêuticos basearam-se no trabalho com gêneros textuais. Primeiramente, pesquisaram-se os gêneros e as temáticas de interesse dos sujeitos, foram feitas leituras de exemplares do gênero escolhido, discussão da estrutura composicional do gênero estudado, e produção do gênero estudado em várias versões e temáticas e, por fim, divulgação da produção.

Dois gêneros textuais foram mais frequentes durante o trabalho neste período. O gênero Quadrinhos foi escolhido pelo grupo na primeira fase da terapia fonoaudiológica e, na segunda fase, o gênero Carta. Este último foi escolhido pelos grupos como uma estratégia de comunicação entre eles, já que na segunda fase terapêutica o grupo inicial havia se desmembrado em dois, com um grupo de três sujeitos frequentando o turno da manhã e os outros dois à tarde.

Concluída a etapa terapêutica, em Junho de 2008 , os sujeitos foram reavaliados com os mesmos procedimentos iniciais de avaliação. Também foi feito um relatório de campo, no qual foram relatadas as sessões na sua íntegra, incluindo as atividades e as reações dos sujeitos a cada proposta diária.

Os pais dos sujeitos foram orientados a incentivar e dar modelo de leitura aos filhos, em entrevistas continuadas que ocorreram mensalmente e em orientações após as sessões terapêuticas.

A presente pesquisa está vinculada ao projeto "Clínica da linguagem escrita: práticas de letramento e gêneros textuais" com aprovação do Comitê de Ética e Pesquisa institucional, sob o no. 0139.0.243.000-07. Os responsáveis assinaram o Termo de Consentimento Livre e Esclarecido permitindo a participação dos sujeitos na pesquisa.

Para a análise dos resultados houve comparação qualitativa da efetividade e eficácia da terapêutica implementada sobre a mudança nos níveis textuais analisados na avaliação inicial. 


\section{RESULTADOS}

Pôde-se observar, após o trabalho terapêutico, melhoras importantes na produção textual de todos os sujeitos que participaram do grupo terapêutico. $O$ interesse e o desejo de ler e escrever aumentou, e a resistência para tarefas envolvendo escrita diminuiu à medida que as atividades foram sendo realizadas.

Um aspecto a ressaltar, foi o de que todos os sujeitos aumentaram o tamanho e a precisão da letra e houve melhor distribuição do texto no papel, demonstrando mais segurança ao escrever. As autocorreções se tornaram frequentes e a preocupação com a progressão e a não repetição foi o aspecto no qual ocorreu maiores mudanças. Os sujeitos apresentaram-se mais preocupados com o planejamento da escrita, tanto nas produções dos trabalhos coletivos, quanto durante as atividades individuais. O item no qual a evolução se deu de forma mais lenta, foi o que se refere à aceitabilidade (ortografia, pontuação).

Outro aspecto observado foi a evolução da interação no grupo. Nas sessões iniciais, havia uma disputa entre os sujeitos 2 e 5 . De modo especial,o sujeito 2 apresentava comportamentos opositivos às propostas e o sujeito 5 buscava ter espaço de destaque junto à terapeuta e aos demais membros do grupo.

Atividades de valorização das idéias dos membros do grupo foram realizadas. Isso fez com que o sujeito 2 se sentisse aceito e acolhido pelo grupo, inibindo seu comportamento opositivo. Esse trabalho beneficiou o sujeito 3 que, a partir deste momento, mostrou-se mais confiante em sugerir atividades, temas e expressar suas opiniões.

O trabalho de cooperação entre os membros e os relatos dos integrantes do grupo sobre as dificuldades escolares fez com que a atitude solidária surgisse entre os participantes, fazendo com que a necessidade primariamente observada de atenção constante da terapeuta, fosse diminuindo, sendo gradativamente substituída pelo apoio recíproco entre os sujeitos.

Após o desmembramento do grupo, houve relatos constantes do sentimento de saudade entre os sujeitos. A escolha do gênero cartas feita pelos próprios integrantes do grupo, foi uma maneira de manter o vínculo estabelecido previamente.

A seguir, na Tabela 2, serão assinalados apenas os aspectos defasados do texto dos sujeitos na avaliação inicial, considerando o protocolo adotado ${ }^{25}$.

\section{Tabela 2 - Protocolo de Lubian aplicado antes e após a intervenção terapêutica}

\begin{tabular}{ccc}
\hline Sujeito & Antes & Depois \\
\hline 1 & Aceitabilidade -3.2 & Aceitabilidade -3.3 \\
\hline \multirow{2}{*}{2} & Aceitabilidade -3.2 & Aceitabilidade -3.2 \\
& Repetição -5.2 & Repetição -5.2 \\
& Progressão -6.2 & Progressão -6.3 \\
\hline \multirow{2}{*}{3} & Aceitabilidade -3.2 & Aceitabilidade -3.2 \\
& Repetição -5.2 & Repetição -5.3 \\
& Progressão -6.2 & Progressão -6.3 \\
\hline & Aceitabilidade -3.1 & Aceitabilidade -3.2 \\
& Repetição -5.1 & Repetição -5.2 \\
\hline \multirow{2}{*}{5} & Progressão -6.1 & Progressão -6.2 \\
\hline & Aceitabilidade -3.2 & Aceitabilidade -3.3 \\
& Progressão -6.2 & Progressão -6.3 \\
\hline
\end{tabular}

Legenda: A1 - aceitabilidade inicial; A2 - aceitabilidade final; R1 - repetição inicial; R2 - repetição final; P1 - progressão inicial; P2 - progressão final.

Sujeito 1: Na avaliação final, observou-se a preocupação do sujeito em ser claro na escrita de seu texto, com letra legível, não cometendo erros ortográficos, fazendo uso de pontuação adequada e conectivos textuais. Apresentou noções temporais e relação causa/consequência nas atitudes de seus personagens. Observou-se também, ampliação do vocabulário escrito.

Sujeito 2: $\mathrm{Na}$ avaliação final, observou-se que não houve mudança de nível quanto à aceitabilidade, mas observou-se melhora qualitativa quanto à distribuição dos parágrafos, adequada pontuação, 
melhora da inteligibilidade da letra. Ocorreu também expansão do vocabulário escrito, uso de marcadores temporais e conectivos frasais. $O$ aspecto referente à repetição apresentou grande evolução, embora não o suficiente para mudança de nível, pois não atingiu todo o texto. Já a progressão evoluiu para o nível máximo.

Sujeito 3: Na avaliação final, notou-se melhora qualitativa do aspecto referente à aceitabilidade, com diminuição dos erros ortográficos, uso de parágrafos e pontuação, mas não o suficiente para que ocorresse mudança de nível. A informatividade dos parágrafos evoluiu, com acréscimos de nova informação a cada frase.

Sujeito 4: Na avaliação final, surgiram conectivos textuais, marcadores temporais, melhora no uso da pontuação e adjetivações. A progressão e a repetição foram os aspectos nos quais ocorreu maior mudança, com aumento da informatividade dos parágrafos e com diminuição da repetição não necessária.

Sujeito 5: $\mathrm{Na}$ avaliação final, observou-se mudança de nível nos dois aspectos defasados, a aceitabilidade e a progressão. Houve melhora da distribuição do texto no papel, uso de letra legível, uso de pontuação adequada, aumento do vocabulário escrito, maior informatividade dos parágrafos. O paciente mostrou também, uma tendência à escrita em forma de crônica.

A Figura 1 mostra o crescimento do grupo na produção textual, na qual são analisados os aspectos referentes à aceitabilidade $(A)$, repetição $(R)$ e progressão $(P)$ inicial (1) e final (2), os quais mostravam-se defasados no início do processo terapêutico. No gráfico, os cinco sujeitos são analisados em conjunto.

Observa-se, na Figura 1, que em relação à aceitabilidade (aspectos formais do texto) um sujeito estava no nível 1 e quatro sujeitos no nível 2 antes da intervenção (A1). Após a intervenção fonoaudiológica (A2), dois sujeitos passaram a estar no nível 3 e os outros três sujeitos demonstraram desempenho no nível 2. A mesma dinâmica é percebida em relação à repetição (uso de elementos coesivos), dois sujeitos permaneceram no nível parcial de desempenho e os outros três atingiram o nível máximo. Quanto à progressão (informatividade progressiva do texto) apenas um sujeito permaneceu no nível 2 de desempenho nessa característica textual e os outros quatro sujeitos alcançaram o nível máximo ao final do processo terapêutico.

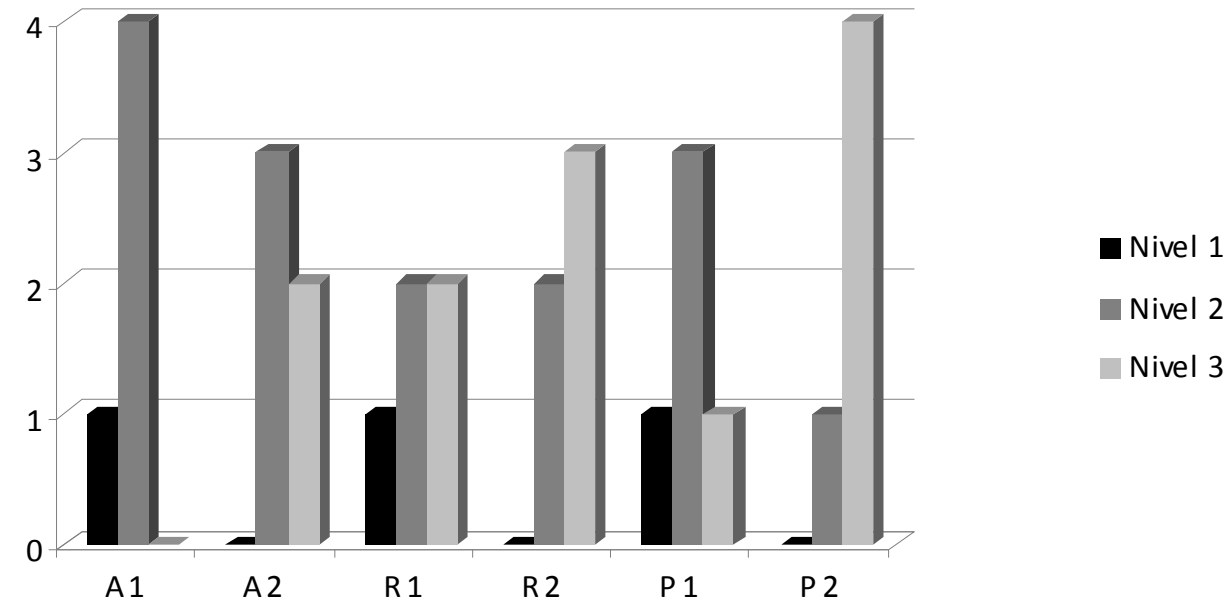

Figura 1 - Evolução textual do grupo quanto os aspectos defasados na avaliação inicial

Cabe ressaltar que, na proposta terapêutica implementada, esperava-se que os níveis que tivessem maior evolução fossem referentes aos aspectos como progressão e repetição bem coordenada, pois são aspectos que se relacionam muito à experiência de leitura e ao conhecimento de recursos linguísticos, ambos muito valorizados ao início do processo terapêutico. No entanto, é considerável a melhoria ortográfica. Obviamente, novas evoluções se fazem necessárias em relação aos aspectos formais, e de organização dos elementos coesivos. Outros recursos estilísticos e o acesso a outros gêneros textuais deverão ser trabalhados. No entanto, o mais importante foi atingido, o desejo de escrever e ter os recursos mínimos necessários para isso. Os sujeitos já possuem a macroestrutura textual básica internalizada, acredita-se que os demais gêneros e os recursos estilísticos virão na medida da experiência. 


\section{DISCUSSÃO}

Percebeu-se que o grupo terapêutico possibilitou relações com grande diversidade de experiências e conhecimentos em torno do objeto de intervenção, a linguagem escrita. Neste estudo, o trabalho em grupo permitiu que os sujeitos transcendessem aos rótulos da escola e de equipes médicas, tão criticados por alguns autores presentes na literatura sobre o tema, pois puderam ressignificar os sentidos atribuídos à queixa a partir de constante diálogo com troca de experiências de situações escolares e familiares ${ }^{22}$.

O objetivo do grupo terapêutico de que os sujeitos passassem a conhecer os diversos aspectos que envolvem a produção textual, discutindo sobre ela concomitante ao momento de sua execução foi atingido. Pelo trabalho com gêneros foi possível instigar a curiosidade dos sujeitos quanto à relação oralidade e escrita, dimensão de circulação do material escrito na sociedade, atentando deste modo com a preocupação com o leitor 1,2,22.

Durante a análise inicial dos textos, observou-se que os sujeitos apresentavam condições de assumirem-se como locutores, porém contatou-se que as produções textuais apresentavam "erros" que comprometeriam a interpretação por parte do leitor, sem conhecimento prévio do assunto. Segundo a literatura, essas inadequações são frequentes no processo de aprendizagem e não podem ser classificadas como patológicas ${ }^{1}$.

Um aspecto a ressaltar é que várias categorias textuais já estavam adequadas ao início da coleta textual, mas o foco na correção da forma por parte dos professores, possivelmente foi um fator inibitório na atribuição de sentidos aos atos de ler e escrever por parte dos sujeitos.

Os autores afirmam que não é apenas retomando tarefas acadêmicas que será possibilitado ao sujeito, na clínica fonoaudiológica, transformar a relação de sofrimento historicamente estabelecida com sua linguagem. Ao contrário, é aproximando-o de situações discursivas cotidianas, em que práticas de letramento significativas estejam presentes, que podemos levá-lo a desconstruir suas ideias preconcebidas acerca de seus processos de elaboração da escrita. A ideia de visitação aos gêneros discursivos é fundamental a esta perspectiva ${ }^{15}$. Tal afirmação se confirmou no grupo estudado, pois o envolvimento em tarefas de linguagem escrita que fizessem sentido com gêneros de seu interesse foi efetivo para que se motivassem a ler e escrever e, a partir disso, os sujeitos procuraram adequar a escrita mostrando uma preocupação em serem claros para com os leitores. Assim, a melhora ortográfica se deu naturalmente pelo desejo de ser compreendido. Dificuldades ortográficas específicas, que permaneceram para alguns sujeitos, tiveram manejo adicional e particular, a cada caso, quando necessário.

Cabe ressaltar que a abordagem do gênero não se deu na perspectiva de sequência didática fixa, mas buscou-se uma atividade que permitisse a flexibilização do processo de leitura/escrita textual.

A mudança de postura adotada pelos familiares quanto às práticas de letramento, a partir de encontros periódicos com a terapeuta, também possibilitou a motivação dos sujeitos para atividades que envolvessem leitura e escrita. Os pais passaram a serem modelos para os filhos, gerando uma rotina familiar com atividades voltadas às práticas de letramento. Portanto, além dos ganhos individuais para cada sujeito, houve um ganho familiar com a intervenção.

A evolução dos sujeitos demonstra que o rótulo de dislexia não cabia nos casos, embora, sem dúvida, necessitassem de auxílio terapêutico. Tal auxílio se fez necessário muito mais pela incapacidade da escola dar conta de seus alunos em sua dinâmica didática, do que pela impossibilidade dos sujeitos aprenderem. Colocam-se então questões éticas a serem discutidas na interface entre clínica de linguagem escrita e a área de educação ${ }^{2}$.

\section{CONCLUSÃO}

O trabalho com gêneros textuais foi fundamental para novas práticas de leitura e escrita no grupo estudado, sendo eficaz como funcionamento terapêutico. Sugere um início do que pode ser um novo olhar sobre o trabalho de linguagem escrita e a necessidade de uma aproximação da área terapêutica com a literatura infanto-juvenil acerca da formação de leitores. Além disso, o estudo de caso demonstrou que não se tratavam de distúrbios, mas práticas de letramento insuficientes os problemas observados nos sujeitos estudados. A mudança nas práticas familiares foi fator importante que, paralelamente ao trabalho em sessão, permitiu a evolução dos sujeitos. No entanto, não se pode excluir totalmente alguma interferência da estimulação no âmbito escolar, que embora não sinalizasse trabalho textual com gêneros pode, via leitura de textos escolares, ter tido influência na evolução dos sujeitos. 


\section{ABSTRACT}

Background: therapy with textual genders in a group of school children. Purpose: to analyze the therapeutic results from the introduction of textual genders as a therapeutical tool in a group of children with difficulties in the acquisition of written language. Procedures: five children enrolled in $5^{\text {th }}$ and $6^{\text {th }}$ grades in distinct schools of public education in the city of Santa Maria/RS, age group ranging between 10 and 13 years and a school report of failure and repetition. The textual production analysis with free thematic was carried out by using the scale of Lubian (2007). The therapeutic intervention occurred between September 2007 and June 2008. The textual production was again analyzed, at the end of the therapeutic work, according to the same scale. Results: the work with textual genders increased motivation for reading and writing and, thus, showed improvement in textual progression and cohesion, as well as adjustment to the formal aspects of writing, such as orthography and punctuation. Group work was essential to enable the members of the group to give a new sense of meaning on the complaint through the constant dialog, with exchange of school and family situations. Conclusion: the therapy with textual genders motivated other practices in reading and writing in the studied group. Additionally, the case studies show no reference to real disorders, but lack of efficient practice in written language.

KEYWORDS: Learning Disorders; Language; Speech Therapy; Reading; Handwriting

\section{REFERÊNCIAS}

1. Massi GA. Dislexia ou processo de aquisição da escrita?. Dist Comun. 2004 dez; 16(3):355-69.

2. Berberian AP, Mori-de-Andelis CC, Massi GA. Violência simbólica nas práticas de letramento. In: Berberian AP, Mori-de-Andelis CC, Massi GA. Letramento: referências em saúde e educação. São Paulo: Plexus; 2006. p. 15-32.

3. Santos GRB. Avaliação de redações nas séries iniciais: frase ou texto como limite? [dissertação]. Passo Fundo (RS): Universidade de Passo Fundo; 2007.

4. Munhoz CMA, Massi G, Berberian AP, Giroto CRM, Guarinello AC. Análise da produção científica nacional fonoaudiológica acerca da linguagem escrita. Pró-Fono. 2007 jul-set; 19(3):249-58.

5. Capellini SA, Padula NAMR, Santos LCA, Lourenceti MD, Carrenho EH, Ribeiro LA. Desempenho em consciência fonológica, memória operacional, leitura e escrita na dislexia familial. Pró-Fono. 2007 out-dez; 19(4):374-80.

6. Cárnio MS, Santos D. Evolução da consciência fonológica em alunos de ensino fundamental. PróFono. 2005 mai-ago; 17(2):195-200.

7. Paula GR, Mota HB, Keske-Soares M. A terapia em consciência fonológica no processo de alfabetização. Pró-Fono. 2005 mai-ago; 17(2):175-84.

8. Jardini RSR, Souza PT. Alfabetização e reabilitação dos distúrbios de leitura/escrita por metodologia fono-vísuo-articulatória. Pró-Fono. 2006; 18(1):69-78.
9. Salgado CA, Capellini SA. Programa de remediação fonológica em escolares com dislexia do desenvolvimento. Pró-Fono. 2008; 20(1):31-6.

10. Reimers F. La buena enseñanza y el éxito escolar de los estudiantes en América Latina. Rev Iberoam Educ. 2003; (31):17-48.

11. Pérez-Jiménez $C$. Formación de docentes para la construcción de saberes sociales. Rev Iberoam Educ. 2003; (33):37-54.

12. Nuñez V. Los nuevos sentidos de la tarea de enseñar. Más allá de la dicotomía 'enseñar vs asistir'. Rev Iberoam Educ. 2003; (33):17-35.

13. Miilher LP, Ávila CRB. Linguistic and narrative variables in oral and written language disorder. PróFono. 2006; 18(2):177-88.

14. Hecht SA, Greenfield DB. Explaining the predictive accuracy of teacher judgments of their students' reading achievement: the role of gender, classroom behavior, and emergent literacy skills in a longitudinal sample of children exposed to poverty. Read Writ. 2002; 15(7-8):789-809.

15. Perotta C, Masini L, Märtz MLW. O trabalho terapêutico fonoaudiológico com a linguagem escrita: considerações sobre a visitação a gêneros discursivos. Dist Comun. 2004 ago; 16(2):181-93.

16. Guarinello AC. O papel do outro na produção escrita de sujeitos surdos. Dist Comun. 2005 ago; 17(2):245-54.

17. Trenche $M C B$, Balieiro $C R$. Da escrita à fala: indícios da presença da escrita no discurso da criança surda. Dist Comun. 2006; 18(1):95-102.

18. Berberian AP, Bortolozzi KB, Guarinello AC. Recurso terapêutico fonoaudiológico voltado à 
linguagem escrita do surdo: o software "Surdo aprendendo em silêncio". Dist Comun. 2006 ago; 18(2):189-99.

19. Serapompa MT, Maia SM. Acolhimento e inclusão: da clínica ao acompanhamento escolar de um sujeito com Síndrome de Down. Dist Comun. 2006 dez; 18(3):313-22.

20. Marcolino J, Catrini M. O jogo entre falar/ escrever/ler na clínica de linguagem com afásicos. Dist Comun. 2006 abr; 18(1):103-9.

21. Barcellos CAP, Freire RM. Assessoria fonoaudiológica na escola: sob o efeito da escrita e sua aquisição. Dist Comun. 2005 dez; 17(3):373-83. 22. Machado MLCA, Berberian AP, Massi G. A terapêutica grupal na clínica fonoaudiológica voltada à linguagem escrita. In: Santana AP, Berberian AP, Guarinello AC, Massi G. Abordagens grupais em fonoaudiologia; contextos e aplicações. São Paulo: Plexus; 2007. p. 58-79.

23. Baktin MO. Os gêneros do discurso. Estética da criação verbal. São Paulo: Martins Fontes; 2003. p. 261-306.

24. Salles JF, Parente MAMP. Processos cognitivos na leitura de palavras em crianças: relações com compreensão e tempo de leitura. Psicol Reflex Crit. 2002; 15(2):321-31.

25. Lubian ME. Processo de produção textual em uma proposta transdisciplinar na $4^{\text {a }}$ série do ensino fundamental. [dissertação]. Passo Fundo (RS): Universidade de Passo Fundo; 2007.

Endereço para correspondência:

Ane Caroline Brisch Schneider

Rua Uruguai, 1361

Santo Augusto - RS

CEP: 98590-000

E-mail: anecarolinebs@yahoo.com.br 